\title{
SmartFarm : IoT-Based Intelligent Plant Watering System
}

\author{
Isbat Uzzin Nadhori ${ }^{* 1}$, M. Udin Harun Al Rasyid ${ }^{2}$, Ahmad Syauqi Ahsan ${ }^{3}$, M. Aji Guna D ${ }^{4}$ Bintang \\ Refani Mauludi $^{5}$ \\ \# Informatic and Computer Engineering Department-Politeknik Elektronika Negeri Surabaya \\ Jl. Raya ITS Keputih Sukolilo Surabaya Indonesia \\ ${ }^{1}$ isbat@pens.ac.id \\ 2 udinharun@pens.ac.id \\ ${ }^{3}$ syauqi@pens.ac.id \\ ${ }^{4}$ ajigunad@gmail.com \\ ${ }^{5}$ bintangrefanimauludi@gmail.com
}

\begin{abstract}
In this article, we present the design of an Internet-of-Things (IoT) based intelligent plant watering system for efficient water use which we call A-SmartFarm. A-SmartFarm provides the right amount of watering volume for plants based on soil moisture, temperature, humidity and air pressure by utilizing the fuzzy method. This system utilizes the Waspmote Agricultural Sensor Kit, Raspberry, automatic sprinklers in the form of solenoid valves, pump motors, and water flow sensors. It also uses a fuzzy method to adjust the exact amount of water volume.

The experimental results show that A-SmartFarm helps increase watering productivity where watering is adjusted to environmental conditions. The experimental results show that the volume of water is not the same for each time. This is different from the manual method of watering which generally uses the same amount of water each time.
\end{abstract}

\section{IoT, Water Management, Android, Sensor, Fuzzy}

\section{INTRODUCTION}

Greenhouses are closed plantation systems that can control environmental conditions that allow off-season farming to increase productivity and are suitable for narrow fields. Automation can be carried out for various operational activities in the Green house which involve many repetitive human activities, including fertilizing, watering, spraying pesticides and others [1]. Proper irrigation is the key to improving the quality and productivity of plants grown in greenhouses [2].

In order to provide precise and precise watering volume, several researchers have worked in this field by experimenting with various parameters, approaches, hardware, platforms and also using analytical methods.

$\mathrm{T}$ B Dwinugroho et al built a prototype of an automatic watering system in a greenhouse using the Zelio SR2B121BD PLC as a sensor and actuator automation processor. There is a soil moisture sensor connected to the Arduino Uno to determine the level of dryness, where this Arduino will send a digital signal to the PLC. The actuator here uses two 5 VDC pumps, the pump will be active based on the time and level of dryness [3].

Ipin Prasojo et al. designed a microcontroller chip that can be programmed to control the watering volume automatically based on the soil moisture sensor. This tool detects whether the soil is dry or not. When the soil is dry, the microcontroller will instruct the solenoid valve to open and water the plants, and when the soil is wet, the solenoid valve will close so the water stops flowing.

Ivony Hari et al developed an intelligent irrigation system using a Programmable Logic Controller (PLC) as a controller and a soil moisture sensor as a tool to measure humidity conditions. The system he developed collects data from the soil moisture sensor, which triggers the valve to perform automatic watering using a sprinkler [5].

Fidaus Kamaruddin et al. developed a proposed IoT-based irrigation management and monitoring system consisting of two main microcontrollers: Sensors and Base Stations. The sensor part is Arduino UNO which is connected to the soil moisture sensor and NRF24L01, soil moisture data is sent to the base station via NRF24L01. The base station section is an Arduino UNO connected to the NRF24L01 and MCU-ESP8266 nodes. The MCU-ESP8266 node can be used to trigger water pumps and also send data to cloud/thinkspeak servers so that the data can be read by Android applications [6].

Devraj Sen et al. developed an irrigation system prototype by utilizing an Arduino UNO-microcontroller board containing an 8-bit microcontroller - ATMEGA328P which is connected to a soil moisture sensor, a wifi module and a motor driver to power the pump. Based on the humidity sensor data, the microcontroller will 
analyze the data and decide whether the pump should start working or not so that the water is not wasted. The Wifi module is used to connect to the nearest wifi so that data can be sent and read by android devices [7].

Based on those research, we propose a real time monitoring system for water requirements in plants that combines sensor data (soil moisture, air temperature and humidity, atmospheric pressure) to determine the volume of watering plants using the fuzzy method. The results of this calculation will be sent by the server, Server will decide to watering through the socket program to the motor pump relay to regulate plant watering. Smartphones that can view data results from the server

\section{PROPOSED SYSTEM DESIGN}

The proposed solution aims to solve the problem of how to determine the right volume of watering plants based on plant conditions, watering schedules and weather predictions with the output in the form of the required volume of water. A system consisting of five important parts of the proposed system is shown in Figure 1.

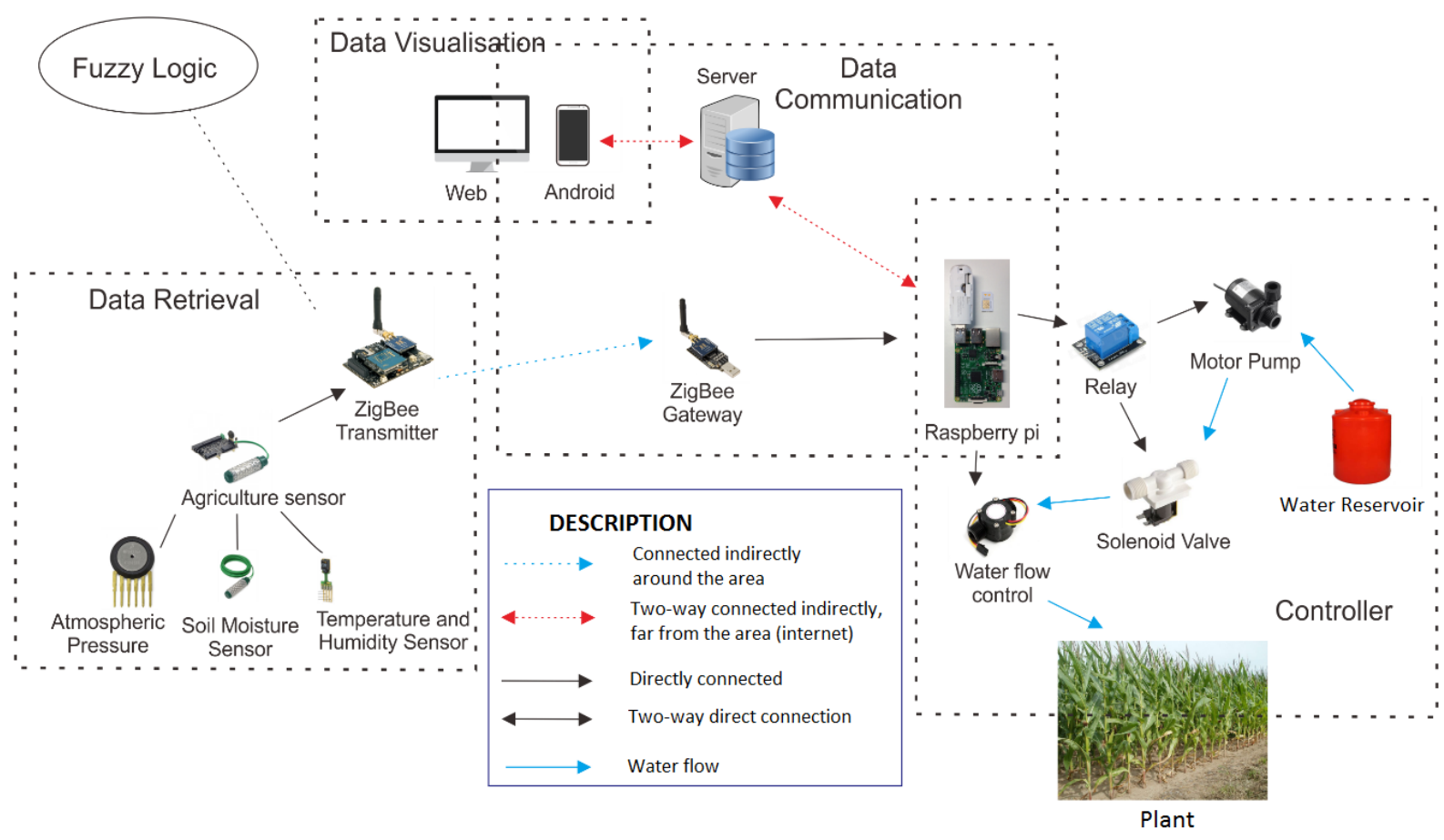

Fig. 1. System Design

This system consists of Waspmote Agriculture Sensor Kit, Raspberry, and watering components such as solenoid valve, motor pump and water flow sensor. Our system has 3 sensors : Soil Moisture sensor, humidity and temperature sensor, and atmospheric pressure sensor. The combination of sensor data is processed using the fuzzy logic method to determine the volume of water requirements in waspmote. The results will be sent to the Raspberry then it will be forwarded to the server. The server will decide watering based on the ideal conditions of the plant. If the conditions do not match the ideal conditions, the server will send a warning notification to the smartphone. The water demand data is used by the server to do watering through the socket program to the relay which functions as a switch. When the relay is on, the pump motor will flow water and the solenoid valve will open so that water will flow to the plant.

\section{EXPERIMENTAL STUDY}

There are 3 fuzzy variables used in the fuzzification process, namely the soil moisture variable, the temperature variable and the volume variable. These three variables will be used in decision making.

Soil moisture sensor is useful for observing the value of moisture in the soil. Soil moisture data is expressed in units of \%RH. And soil moisture sensor data is divided into three categories, namely dry, moist, and wet. To provide a clear picture of the fuzzy set of soil moisture sensors, it can be described in the membership function shown in Figure 2. 


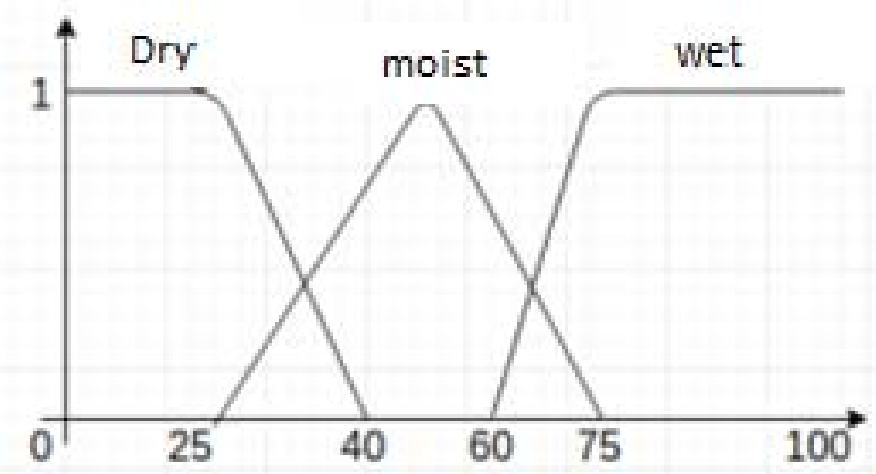

Fig. 2. Fuzzy set of soil moisture variables $(\% \mathrm{RH})$

The temperature sensor is useful for observing the value of the air temperature around the monitored environment. Temperature sensor data is divided into three categories, namely cold, cool, normal, warm and hot. To provide a clear picture of the fuzzy set of temperature sensors, it can be described into the membership function shown in Figure 3.

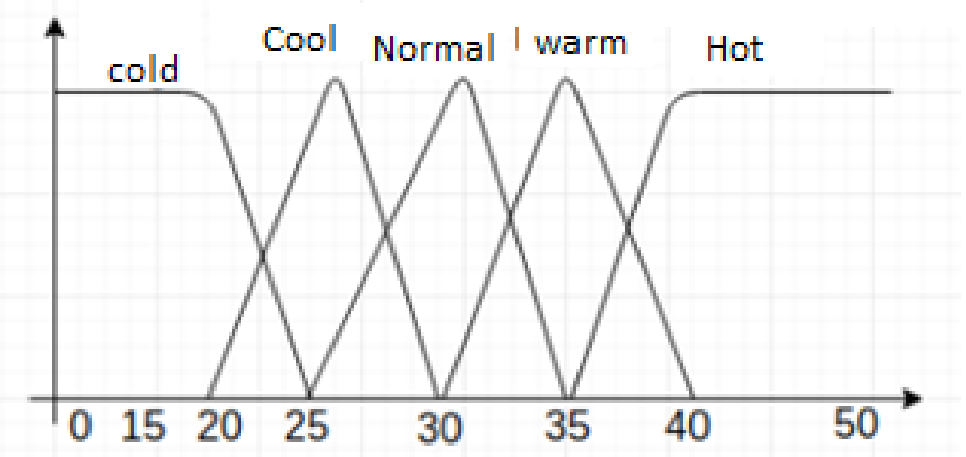

Fig. 3. Fuzzy set for temperature variable ( C )

This volume set is the result set that is used to determine the final result of this fuzzy process.

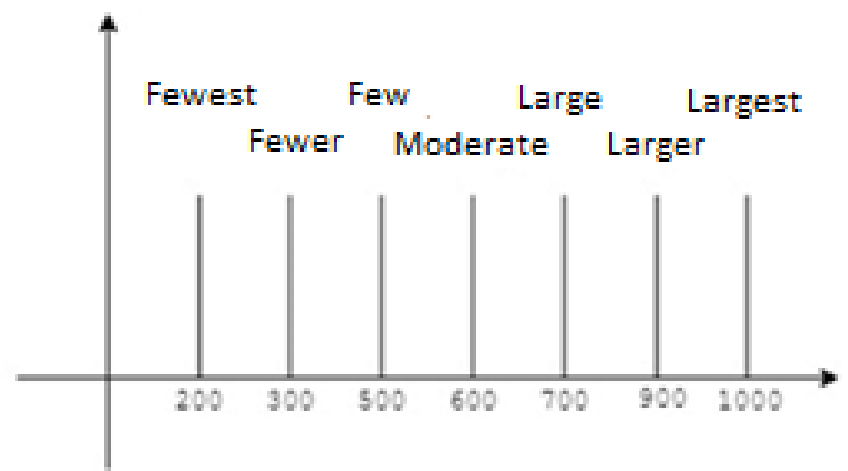

Fig. 4. Fuzzy set for volume variable ( $\mathrm{ml})$

After the fuzzification stage, fuzzy rules will be formed. The formation of this fuzzy rule is done to express the relationship between input and output. The operator used to connect two inputs is the AND operator, and the one that maps between input and output is IF-THEN.

The number of rules formed is obtained from the multiplication of each membership of the fuzzy variable. In this study, the number of rules formed was obtained from 2 parameters, so there were 15 rules. Examples of rules that have been formed can be seen in Table 1 
TABLE I

Fuzzy Logic Rules

\begin{tabular}{|c|c|c|c|c|c|}
\hline & Cool & Mild & Normal & Warm & Hot \\
\hline Wet & Smallest & Small & Smaller & Medium & Large \\
\hline Moist & Small & Smaller & Medium & Large & Larger \\
\hline Dry & Smaller & Medium & Large & Larger & Largest \\
\hline
\end{tabular}

After getting the rules used in the inference process, the next thing to do is to aggregate or combine the output of all the rules called the Composition stage. The result of this stage is the $\alpha$-predicate of each rule.

After performing the Composition stage which produces $\alpha$-predicate from each rule, then the next step is to enter the final stage, namely Defuzzification. This defuzzification process is a sharp output calculation process. The calculation is done by averaging all $\mathrm{z}$ with the following formula:

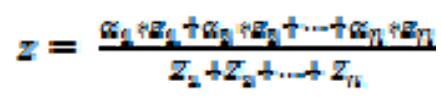

Two application interfaces are prepared: web-based and android-based which can monitor plant conditions and determine the amount of water needed by plants.

The web application is used to display overall factory condition data. Starting from air temperature, humidity, soil moisture, air pressure, and time. Data is retrieved from a certain time to be sent to the server

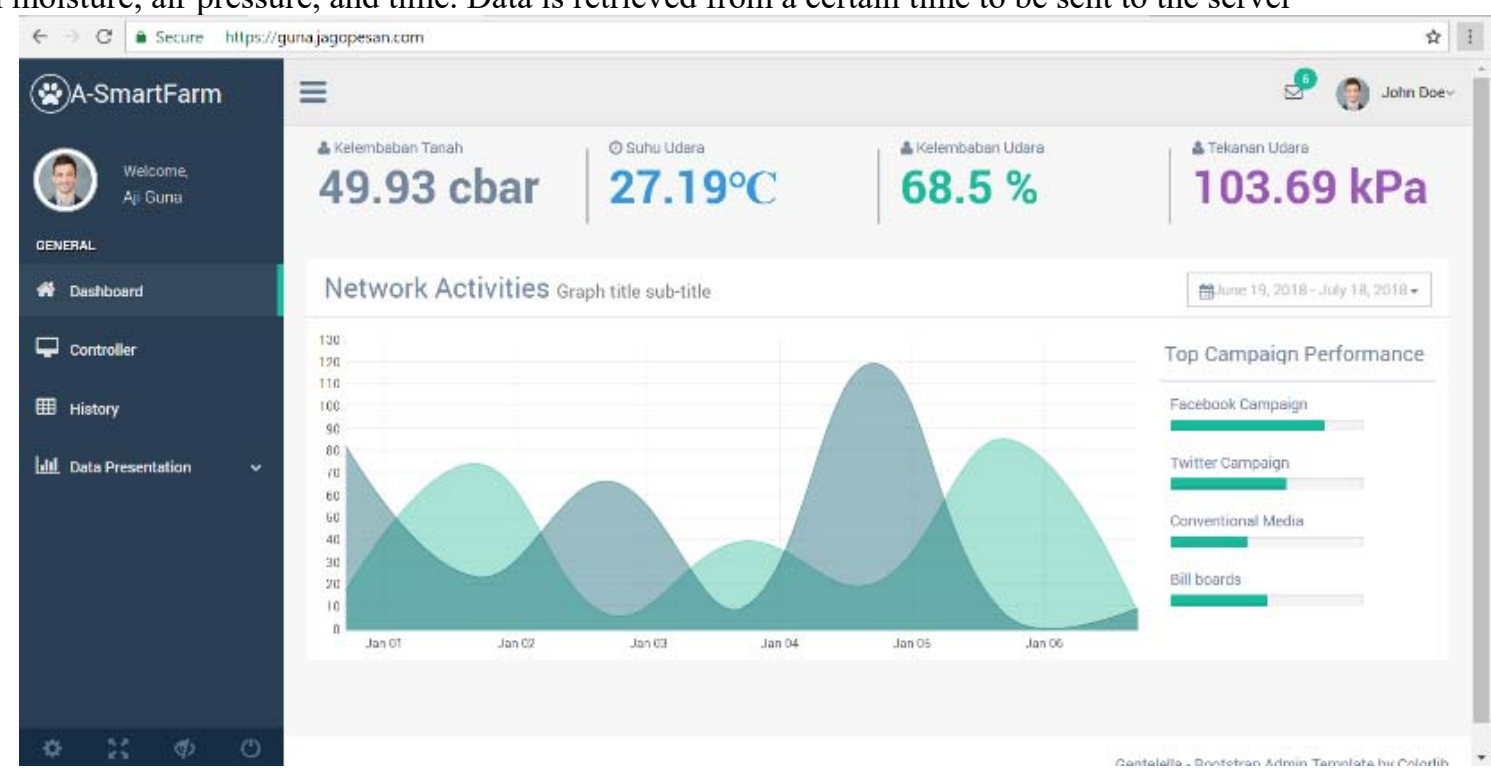

Fig. 5. Web application's dashboard interface

The android application is used to see the current condition of the plant. An example of the results of an android application can be seen in Figure 5. This dashboard shows the condition of plants in the form of temperature, humidity, soil moisture, and air pressure 


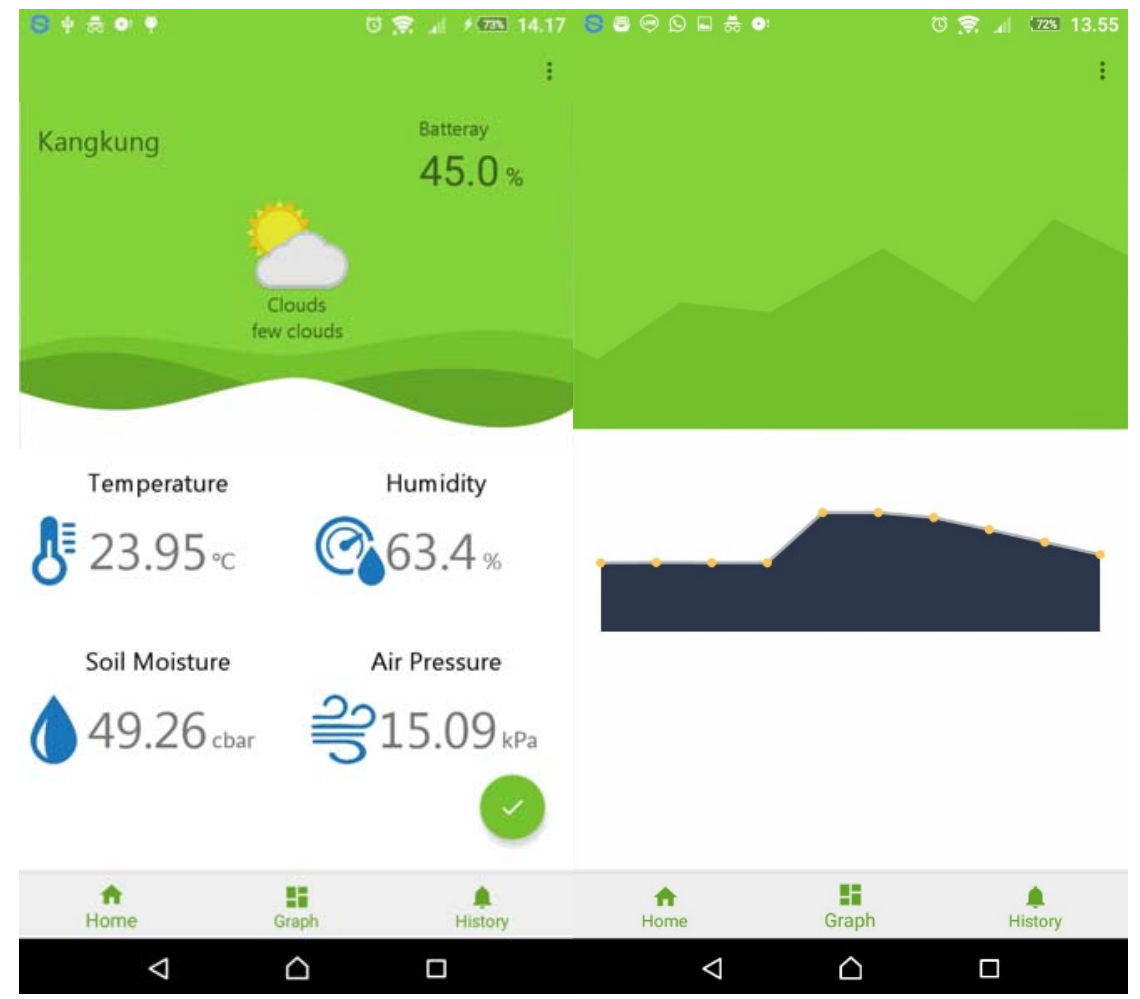

Fig.6. Android-based application dashboard

In the history menu there is data generated from the log of watering activities that have been carried out. The contents of the history consist of the time and volume of water released.

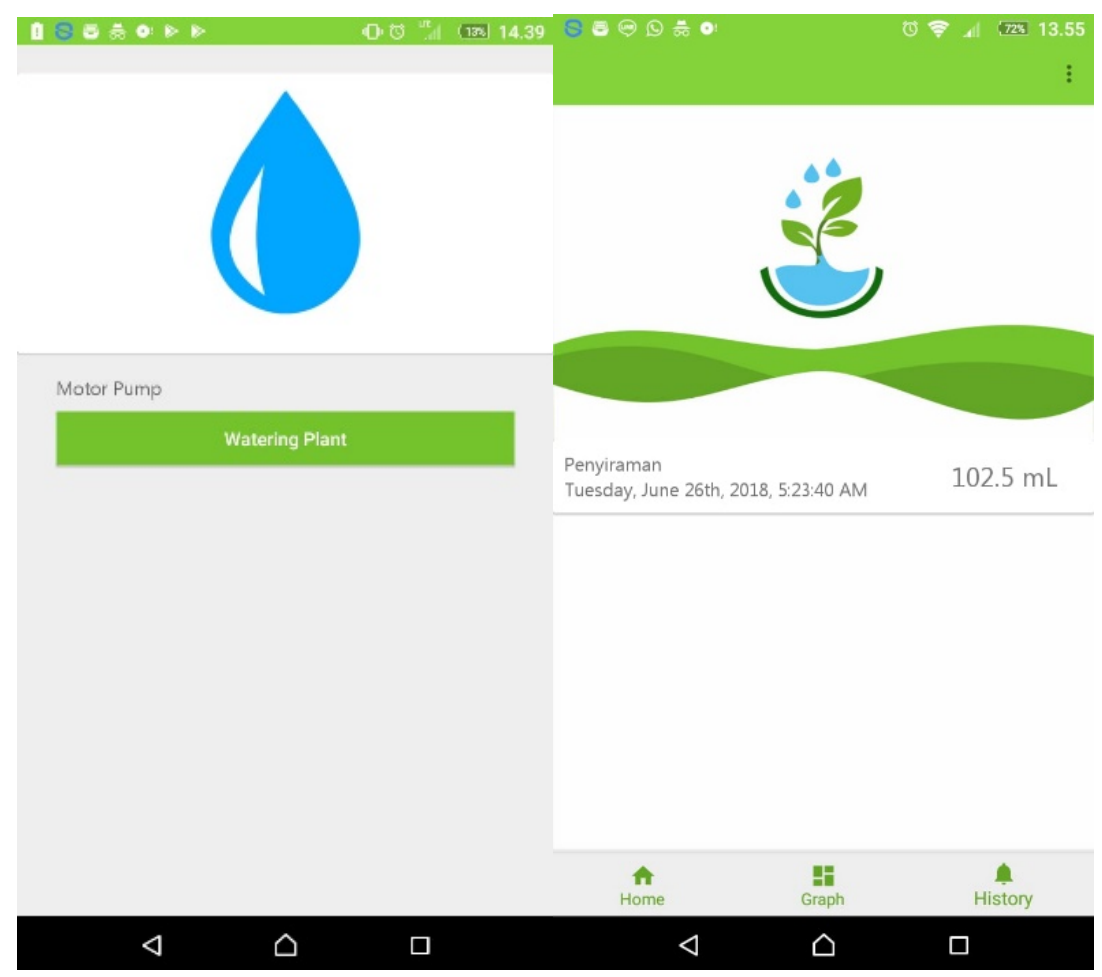

Fig.6. Display on graph and to turn on watering device

In the watering view the plants are shown in the picture. 7. It is used to activate the solenoid valve and motor pump. 
In addition to monitoring plants, further analysis of watering data is carried out by doing several waterings with the volume of water indicated by the application. Here are the results of the watering experiments that have been carried out.

TABLE 2

Watering Result

\begin{tabular}{|c|c|r|r|r|r|r|r|r|}
\hline No & Date & $\begin{array}{c}\text { Temperature } \\
\text { before } \\
\mathbf{( \% R H )}\end{array}$ & $\begin{array}{c}\text { Previous } \\
\text { humidity } \\
(\mathbf{\%} \mathbf{R H})\end{array}$ & $\begin{array}{r}\text { Fuzzy } \\
\text { Value }\end{array}$ & $\begin{array}{c}\text { Water } \\
\text { Volume }\end{array}$ & $\begin{array}{c}\text { Temperature } \\
\text { after } \\
\left({ }^{\circ} \mathbf{C}\right)\end{array}$ & $\begin{array}{c}\text { Humidity } \\
\text { after } \\
(\mathbf{\%} \mathbf{R H})\end{array}$ & $\begin{array}{c}\text { Humidity } \\
\text { difference } \\
(\mathbf{\%} \mathbf{R H})\end{array}$ \\
\hline 1 & $\begin{array}{c}18- \\
\text { July }\end{array}$ & 27,50 & 66,20 & 2,34 & 467 & 26,20 & 73,70 & 7,50 \\
\hline 2 & $\begin{array}{c}21- \\
\text { July }\end{array}$ & 23,56 & 69,70 & 2,39 & 478 & 28,25 & 73,30 & 3,60 \\
\hline 3 & $\begin{array}{c}22- \\
\text { July }\end{array}$ & 23,51 & 69,60 & 2,40 & 480 & 28,22 & 74,40 & 4,80 \\
\hline 4 & $\begin{array}{c}23- \\
\text { July }\end{array}$ & 28,05 & 70,90 & 2,17 & 434 & 27,53 & 78,60 & 7,70 \\
\hline \multicolumn{2}{|c|}{ Rate } & $\mathbf{2 5 , 6 6}$ & $\mathbf{6 9 , 1 0}$ & $\mathbf{2 , 3 2}$ & $\mathbf{4 6 4 , 7 5}$ & $\mathbf{2 7 , 5 5}$ & $\mathbf{7 6 , 8 5}$ & $\mathbf{7 , 7 5}$ \\
\hline
\end{tabular}

\section{IV.DISCUSSION}

It can be seen from table 2 column "previous humidity" that the value of air humidity is always less than $70 \% \mathrm{RH}$ which is the lower limit of ideal humidity for plants. Then the table also displays temperature data, fuzzy values, and water volume data. In the column "humidity after" it can be seen that the value of air humidity on the prototype always rises to above $70 \% \mathrm{RH}$. The value of the increase in air humidity before and after watering contained in the "difference" column varied. The smallest increase occurred on July 21, which was 3.6 levels. While the biggest increase occurred on July 23 with 7.7 levels. Furthermore, the volume column states that the minimum watering volume is $434 \mathrm{~mL}$ on 23 July and the highest watering volume is $480 \mathrm{~mL}$ on $22 \mathrm{July}$.

Then in the last row there is an average for each column. In the column "temperature before" the average value is 25.66 . In the "previous humidity" the average value is 69.10. The fuzzy value is 2.32. Meanwhile, after watering the column "after temperature" is 27.55. This is not based on the effect of watering but the condition of the ambient air temperature at that time. Then in the column "humidity after" the average is 76.85 , where the data is based on the effect of watering. And finally there is a column for comparison of humidity after and before with a value of 7.75 .

\section{CONCLUSION}

The proposed system provides an effective, water-saving system for condition monitoring and watering of plants. This system uses the Waspmote Agriculture Sensor Kit, Raspberry, a sprinkler device in the form of a solenoid valve, a motor pump, and a water flow sensor by utilizing a fuzzy method to adjust the water volume. The accuracy of the sensors for measuring plant conditions in our system is reliable and efficient. This system can assist farmers in overcoming irrigation problems in the agricultural sector. In subsequent developments, this system can be used in greenhouses, hydroponics, or other sectors. A network system needs to be created where the acquired data can be accessed by the individuals concerned from username authentication to security.

\section{ACKNOWLEDGMENT}

This research was supported in part by Ministry of Research and Technology of the Republic of Indonesia, under scheme Higher Education Excellence Applied Research 'Penelitian Dasar Unggulan Perguruan Tinggi (PDUPT)', No. Grant B/112/E3/RA.00/2021.

\section{REFERENCES}

[1] Hatem Elaydi, An Automated Irrigation System for Greenhouses, American Journal of Electrical and Electronic Engineering, 2017, Vol. 5, No. 2, 48-57

[2] E.H. Simonne, M.D. Dukes, and L. Zotarelli. "Principles and practices of irrigation management for vegetables," Horticultural Sciences Dept., UF/IFAS, Fla. Coop. Ext. Serv., Publication no. AE260, 2010, Chapter 3, pp. 1-8

[3] T B Dwinugroho, Y T Hapsari and Kurniawanti, Greenhouse automation: smart watering system for plants in greenhouse using programmable logic control (PLC), Journal of Physics: Conference Series, IOP Publishing, 2020

[4] Ipin Prasojo, Andino Maseleno, Omar tanane, Nishith Shahu, Design of Automatic Watering System Based on Arduino, Journal of Robotics and Control (JRC), March 2020

[5] Ivony Hari, Elita Rahmarestya, Harsono Harsono, Development of IoT Based Smart Irrigation System with Programmable Logic Controller, International Journal of Agriculture System, June 2021

[6] Fidaus Kamaruddin, Nik Noordini Nik Abd Malik, Noor Asniza Murad, Nurul Mu'azzah Abdul Latiff, Sharifah Kamilah Syed Yusof, Shipun Anuar Hamzah, IoT-based intelligent irrigation management and monitoring system using Arduino, Telkomnika, October 2019

[7] Devraj Sen, Madhulika Dey, Shubham Kumar, Dr.C.S.Boopathi, Smart Irrigation Using IoT, International Journal of Advanced Science and Technology, 2020 